\title{
The prevalence of comorbidity and predictors in ankylosing spondylitis
}

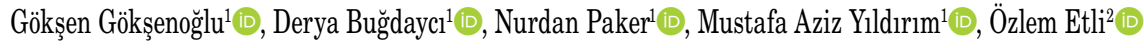 \\ ${ }^{1}$ Department of Physical Medicine and Rehabilitation, İstanbul Physical Medicine and Rehabilitation Training and Research Hospital, İstanbul, Turkey \\ ${ }^{2}$ Department of Pathology, Pendik State Hospital, İstanbul, Turkey
}

Received: February 28, 2018 Accepted: June 09, 2018 Published online: August 21, 2018

\begin{abstract}
Objectives: The aim of the present study was to investigate the prevalence of comorbidities and related factors in patients with ankylosing spondylitis (AS).

Patients and methods: Between June 2013 and January 2014, a total of 100 patients with AS (64 males, 36 females; mean age $43.1 \pm 10.7$ years; range, 25 to 73 years) who were under routine follow-up in the outpatient clinic were included in this cross-sectional study. The demographic characteristics of the patients were recorded. The Ankylosing Spondylitis Disease Activity Scale (ASDAS), Bath Ankylosing Spondylitis Disease Activity Index (BASDAI), Bath Ankylosing Spondylitis Functional Index (BASFI), and Bath Ankylosing Spondylitis Metrology Index (BASMI) scores were calculated. Comorbidities were evaluated using the modified Cumulative Illness Rating Scale (CIRS). Both the number and severity of the affected systems were scored.

Results: The mean amount of cigarette consumption was $17.3 \pm 13.5$ pack/year. The mean disease duration was $191.3 \pm 122.4$ months. The BASFI, BASDAI, BASMI, and ASDAS-C-reactive protein scores were 3.4 $\pm 2.3,3.7 \pm 2.0,4.5 \pm 1.8$, and 2.5 \pm 0.9 , respectively. The mean number of system-related problems was 4.3 (range, 1 to 11). The mean CIRS scores for the severity of comorbidities were $7.36 \pm 3.48$ (range, 3 to 23 ). The most frequent system combinations were hematopoietic, eye, ear, nose and throat, and upper gastrointestinal in 11 patients, hematopoietic, respiratory and upper gastrointestinal in 11 patients, and hematopoietic, respiratory and eye, ear, nose and throat in 10 patients. When the estimated total CIRS scores was assessed in the multivariate reduced model, age, disease duration, and BASFI values showed a significant independent effect.

Conclusion: Our study results showed that the frequency of comorbidities was more than four, although the severity of system problems were mild in AS patients as measured by CIRS. The most frequently involved systems included hematopoietic, upper gastrointestinal, lower gastrointestinal, renal, and musculoskeletal-skin systems. Age, disease duration, and BASFI scores were found to be predictors of comorbidities in our patients.
\end{abstract}

Keywords: Ankylosing spondylitis, comorbidity, cumulative illness rating scale, predictors.

Comorbidity often arise when a particular disease leads to other complications in patients. ${ }^{[1]}$ Comorbidity is common in elderly, particularly in individuals older than 65 years with hypertension, coronary artery disease, cerebrovascular accidents, and diabetes. ${ }^{[2]}$

The prevalence of comorbidities is also higher in patients with inflammatory arthritis. ${ }^{[3]}$ In a chronic inflammatory disease, such as ankylosing spondylitis (AS), certain comorbidities including osteoporosis and cardiovascular diseases are common than the normal population in the same age group due to the underlying pathophysiological mechanisms. ${ }^{[4,5]}$ In a previous study, the rates of hypertension, peptic ulcer, and headache in AS were reported as $16.4 \%, 13.9 \%$, and $10.2 \%$, respectively, and these rates were higher than the patients in the same age group. ${ }^{[6]}$

Comorbidities have an adverse effect on the functional status and the quality of life. The level of physical function is lower in patients with arthritis in the presence of comorbidities. ${ }^{[7]}$ The recognition of factors associated with comorbidities is clinically useful. There are certain scales which are used to evaluate comorbidities. These scales help to define both the number and the severity of the comorbidities.

Corresponding author: Gökşen Gökşenoğlu, MD. İstanbul Fizik Tedavi Rehabilitasyon Eğitim ve Araştırma Hastanesi, Fizik Tedavi ve Rehabilitasyon Kliniği, 34186 Bahçelievler, İstanbul, Turkey. e-mail: goksengoksenoglu@hotmail.com 
The Cumulative Illness Rating Scale (CIRS) is one of them which helps to determine the number of specific system problems and their severity. ${ }^{[8,9]}$ In the original CIRS, 13 system-related disorders can be evaluated. ${ }^{[10]}$ In the modified CIRS, totally 14 system problems including cardiac, vascular, respiratory, otorhinolaryngology, upper gastrointestinal, lower gastrointestinal, hepatic and pancreatic, renal, genitourinary, musculoskeletal and dermatologic, neurology, endocrinology, metabolic, breast, and psychiatric can be evaluated. The CIRS is a userfriendly multi-morbidity and comorbidity scale which can fully evaluate organ systems providing accessibility advantages to the users. ${ }^{[11]}$

In the present study, we aimed to investigate the prevalence and severity of the comorbidities using the CIRS and to identify possible predictors in AS patients.

\section{PATIENTS AND METHODS}

Between June 2013 and January 2014, a total of 100 patients with AS (64 males, 36 females; mean age $43.1 \pm 10.7$ years; range, 25 to 73 years) who were under routine follow-up in the outpatient clinic were included in this cross-sectional study. The AS diagnosis was based on the modified New York criteria for AS or Assessment of SpondyloArthritis International Society (ASAS) classification criteria. A written informed consent was obtained from each patient. The study protocol was approved by the Bakırköy Sadi Konuk Training and Research Hospital Ethics Committee (No. 2018/08). The study was conducted in accordance with the principles of the Declaration of Helsinki.

The demographic characteristics, smoking habits (duration, quantity), weekly working hours, and drug treatments were questioned in all patients. The clinical features related to the disease were recorded. The routine physical and detailed musculoskeletal system examinations of the patients were performed. The Ankylosing Spondylitis Disease Activity Scale (ASDAS), Bath Ankylosing Spondylitis Disease Activity Index (BASDAI), Bath Ankylosing Spondylitis Functional Index (BASFI), and Bath Ankylosing Spondylitis Metrology Index (BASMI) scores were calculated for all patients. Comorbidities were evaluated using the modified CIRS. The modified CIRS identifies 14 items corresponding to the different systems. Each system is scored between 0 and 4 according to the severity of involvement. The total score of systemic disorders varies in the range of 0 to 56 . Higher scores indicate higher and more severe systemic problems.
The laboratory results of erythrocyte sedimentation rate (ESR), C-reactive protein (CRP), complete blood count, routine biochemical laboratory tests, blood uric acid level, complete urine test, and human leukocyte antigen-B27 (HLA-B27) results were recorded.

\section{Statistical analysis}

The Kolmogorov-Smirnov test was used to test whether the data were normally distributed. Descriptive data were presented in arithmetic mean and standard deviation (SD) for normally distributed variables or median and min-max for non-normally distributed variables. For non-normally distributed data, logarithmic transformation was conducted for total CIRS scores. After the transformation, advanced analyses were performed. Correlation coefficients were calculated with the Pearson test for normally distributed variables, and with the Spearman test for non-normally distributed variables. A multiple linear regression (MLR) model was used to identify independent predictors of CIRS and to identify confounding effects between potentially independent predictors. The natural logarithmic transformation was applied to make the dependent variable (CIRS) data fit the normal distribution. The suitability of MLR assumptions were confirmed by following tests/plots. A scatterplot of standardized residuals ( ${ }^{\star}$ ZRESID) versus standardized predicted values ( ${ }^{\star} Z$ PRED) was used to test assumptions of heteroscedasticity, linearity. Multivariate normality was tested by probability-probability (P-P) plot of regression standardized residual. Auto-correlation was checked by Durbin-Watson test. Multicollinearity assumption was tested using the variance inflation factor (VIF) values.

A stepwise method was used to construct MLR models. Variables can be entered or removed from the model depending on the significance (probability) of the $F$ value. A variable was entered into the model if the probability of its score statistic was less than the entry value (0.05), and it was removed if the probability was greater than the removal value (0.1). Model fit was assessed using appropriate and goodnessof-fit statistic. Power of the study was calculated with $G^{\star}$ Power version 3.1.9.2 software (Heinrich Heine University, Dusseldorf, Germany). For the given effect size (0.82), sample size (100), and alpha (0.05, two-tailed), the power was calculated as 0.99 . Data were analyzed using the IBM SPSS, version 22.0 (IBM Corp. Armonk, NY, USA). A $p$ value of $<0.05$ was considered statistically significant. 
Table 1. Demographic and clinical characteristics of patients

\begin{tabular}{|c|c|c|c|}
\hline & Mean \pm SD & Median & Min-Max \\
\hline Age (year) & $43.1 \pm 10.7$ & - & - \\
\hline Height $(\mathrm{cm})$ & $165.5 \pm 10.0$ & - & - \\
\hline Weight $(\mathrm{kg})$ & $75.1 \pm 13.8$ & - & - \\
\hline Education duration (year) & - & 5.5 & $0.0-15.0$ \\
\hline Weekly working time (hour) & - & 25.0 & $0.0-98.0$ \\
\hline Duration of diagnosis (month) & - & 84.0 & $1.0-504.0$ \\
\hline Symptom duration (month) & $191.3 \pm 122.4$ & - & - \\
\hline Smoking (pack/year) & $17.3 \pm 13.5$ & - & - \\
\hline Sedimentation rate $(\mathrm{mm} / \mathrm{hr})$ & $27.6 \pm 20.0$ & - & - \\
\hline C-reactive protein $(\mathrm{mg} / \mathrm{dL})$ & - & 0.53 & $0.0-6.27$ \\
\hline Fatigue & - & 5.0 & $0.0-10.0$ \\
\hline Pain (night) & - & 3.0 & $0.0-10.0$ \\
\hline Pain (total) & - & 4.0 & $0.0-10.0$ \\
\hline Patient (global) & - & 4.0 & $0.0-10.0$ \\
\hline Physican (global) & - & 4.0 & $0.0-8.0$ \\
\hline Bath Ankylosing Spondylitis Functional Index & - & 3.1 & $0.0-10.0$ \\
\hline Bath Ankylosing Spondylitis Disease Activity Index & $3.7 \pm 2.0$ & - & - \\
\hline Ankylosing spondylitis specific quality of life & $6.7 \pm 5.4$ & - & - \\
\hline Bath Ankylosing Spondylitis Metrology Index & $4.5 \pm 1.8$ & - & - \\
\hline Ankylosing Spondylitis Disease Activity Scale C-reactive protein & $2.5 \pm 0.9$ & - & - \\
\hline Ankylosing Spondylitis Disease Activity Scale erythrocyte sedimentation rate & $2.7 \pm 0.9$ & - & - \\
\hline Cumulative Illness Rating Scale total score & $7.36 \pm 3.48$ & - & - \\
\hline
\end{tabular}

SD: Standard deviation; Min: Minimum; Max: Maximum; Mean: Arithmethic mean.

\section{RESULTS}

The demographic and clinical characteristics of the patients are presented in Table 1 . Of the patients, 88 were married and 12 were single. A total of 38 patients were non-smokers, while 44 were smokers. Eighteen patients were also former smokers. A total of $78 \%(n=78)$ of the patients were HLA-B27 positive. Of the patients, 24 (24\%) had peripheral arthritis, $20(20 \%)$ had uveitis, two (2\%) had ulcerative colitis, and two (2\%) had Crohn's disease. Seventy-six percent of the patients had no joint involvement. Thirty-one patients had knee arthritis. Eleven patients had the involvement of the ankle. Arthritis was observed in the shoulder, elbow, and hand joints of each patient. Forty-seven percent of the patients were using biological agents. Eight percent were using biological agent and non-inflammatory drugs (NSAIDs), 23\% were using sulfasalazine and NSAIDs, and $15 \%$ were using NSAIDs alone. Four patients were only using sulfasalazine. Three patients were not using any drug.
Comorbidities of the patients are summarized in Table 2. Of the patients, $60 \%$ had a comorbid disease. Comorbidities were found in $51.6 \%$ and $75 \%$ of male and female patients, respectively (Yates corrected chi-square, $\mathrm{p}=0.037)$. The mean number of system-related

Table 2. Comorbidities

\begin{tabular}{lcc}
\hline Disease & $\mathrm{n}$ & $\%$ \\
\hline Gastritis & 41 & 41.0 \\
Hypertension & 17 & 17.0 \\
Hypothyroidism & 8 & 8.0 \\
Asthma & 6 & 6.0 \\
Diabetes mellitus & 6 & 6.0 \\
Aortic insufficiency & 5 & 5.0 \\
Hyperlipidemia & 3 & 3.0 \\
Arrhythmia & 2 & 2.0 \\
Coronary artery disease & 1 & 1.0 \\
Chronic renal failure & 1 & 1.0 \\
Other & 16 & 16.0 \\
\hline
\end{tabular}


Table 3. Pearson (r) and Spearman's (rho) correlation coefficients between Ln-transformed total score of Cumulative Illness Rating Scale and the variables

\begin{tabular}{lccc}
\hline Variables & $\mathrm{r}$ & rho & $p$ \\
\hline Age $^{*}$ & 0.617 & - & $<0.001$ \\
Height $^{*}$ & -0.328 & - & 0.001 \\
Education duration $^{* *}$ & - & 0.206 & 0.039 \\
Weekly working time $^{* *}$ & - & 0.452 & $<0.001$ \\
Smoking (pack/year) $^{* *}$ & - & 0.329 & 0.001 \\
Symptom duration $^{*}$ & 0.528 & - & $<0.001$ \\
Duration of diagnosis $^{* *}$ & - & 0.505 & $<0.001$ \\
Bath Ankylosing Spondylitis Functional Index $^{* *}$ & - & 0.243 & 0.015 \\
Bath Ankylosing Spondylitis Metrology Index $^{*}$ & 0.524 & - & $<0.001$ \\
\hline
\end{tabular}

Ln: Logarithm natural; ${ }^{*}$ Pearson correlation; ${ }^{* *}$ Spearman correlation.

Table 4. Multiple linear regression models for Ln-transformed total score of Cumulative Illness Rating Scale

\begin{tabular}{lcccc}
\hline Independent variables & \multicolumn{1}{c}{ Standardized coefficients (Beta) } & $\mathrm{t}$ & $\mathrm{p}$ & Collinearity statistics VIF \\
\hline Constant & & 4.944 & $<0.001$ & $<0.001$ \\
Age & 0.490 & 5.421 & 0.002 & 1.502 \\
BASFI score & 0.231 & 3.109 & 0.017 & 1.019 \\
Disease duration & 0.220 & 2.419 & 1.521 \\
\hline
\end{tabular}

Ln: Logarithm natural; VIF: Variation inflation factor; BASFI: Bath Ankylosing Spondylitis Functional Index.

problems was 4.3 (range, 1 to 11) according to the CIRS scores. The median total comorbidity score was 7.0 (range, 3.0 to 23.0). System problems according to their frequencies were four systems in 22 patients, five systems in 21 patients, three systems in 20 patients, two systems in 16 patients, six systems in eight patients, seven systems in seven patients, 10 systems in two patients, eight systems in two patients, one system in one patient, and 11 systems in one patient. The most frequent comorbidities were related with hematopoietic, eye, ear, nose and throat, and upper gastrointestinal in 11 patients and hematopoietic, respiratory, and upper gastrointestinal in 11 patients, and hematopoietic, respiratory and eye, ear, nose and throat in 10 patients. A positive correlation between total score of logarithm natural (Ln) (CIRS) and age, disease duration, time from diagnosis, BASFI and BASMI scores and a negative correlation between total score of Ln (CIRS) and height and weekly working hours were found (Table 3).

A positive correlation was found between total score of Ln (CIRS) and age, weekly working hours, smoking (pack/year), disease and time from diagnosis, BASFI and BASMI scores and a negative correlation was found between total score of
Ln (CIRS) and height. The MLR analysis indicated that age, disease duration, and BASFI scores were significant predictors of total score of Ln (CIRS) (adj R2=0.46, $\mathrm{F}=29.2, \mathrm{p}=0.0001$, Durbin-Watson: 1.512). Also, the positive regression coefficient (beta) showed a positive correlation between total score of Ln (CIRS) and age, BASFI scores, and disease duration (Table 4). A scatterplot of MLR analysis was shown in Figure 1.

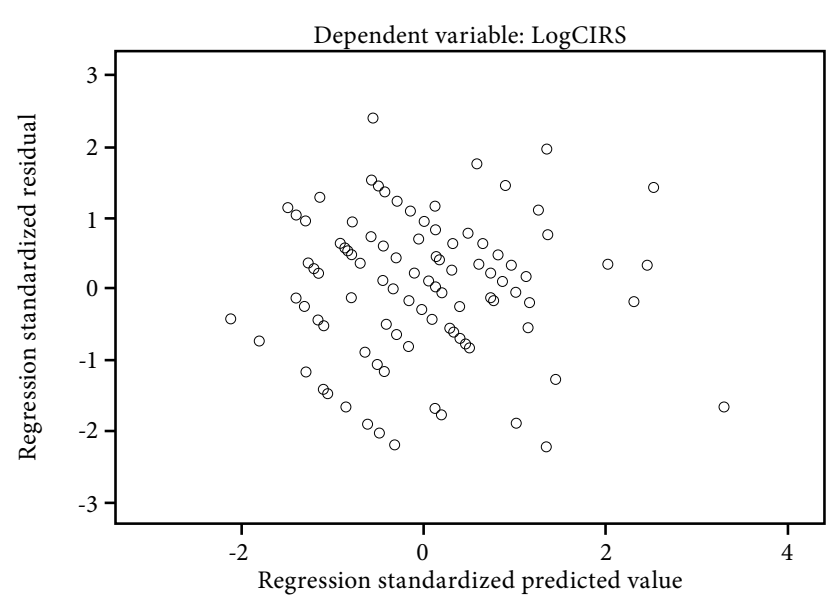

Figure 1. Scatterplot of the multiple regression analysis. CIRS: Cumulative Illness Rating Scale. 


\section{DISCUSSION}

In the present study, we found that the mean number of system problems was higher than four in AS patients. However, the mean CIRS total score for the severity of system disorders was seven, which was not high. As most of the patients with AS had mild systemic problems in our study, the CIRS total score was below 10 . The CIRS total score $>10$, usually shows four to five system-related disorders. In case of severe comorbidities in different organ systems, the CIRS total score can be found between 25 and 30. ${ }^{[12]}$ In this study, the most common system problems were related with hematopoietic, upper gastrointestinal, lower gastrointestinal, renal and musculoskeletalskin. Moreover, most frequent comorbidities were gastritis (41\%) and hypertension (17\%). Hypertension (22.8\%), thyroid disorders (12.8\%), and type 2 diabetes mellitus (11.4\%) are relatively common in patients with AS. ${ }^{[13]}$ Garip et al. ${ }^{[14]}$ reported that the most common comorbidities in AS were peptic ulcer (20.9\%), hypertension (20\%), lung disease (15.6\%), diabetes mellitus (13.6\%), osteoporosis (10.9\%), ischemic heart disease (10\%), renal disease, and cancers, according to their frequency.

In our study, hematopoietic system was affected frequently in AS. Therefore, anemia was diagnosed in almost half of the patients. Anemia may develop in autoimmune diseases accompanied by chronic inflammation. Although anemia is common in patients with AS, it may be frequently overlooked due to a mild decrease in hemoglobin levels. In the previous studies, the ratios of anemia were reported in the range of 20 to $27.9 \%$ in patients with $\mathrm{AS}^{[15,16]}$ In our study, anemia was more frequent than reported findings.

In the present study, the upper gastrointestinal system disorder was found in $42.1 \%$ of the patients. In a previous population-based study including patients with AS, the ratio of peptic ulcer was reported as $13.9 \%$ among the patients, indicating a significantly higher ratio than that of the control group. ${ }^{[6]}$ The high ratio of upper gastrointestinal system involvement might be related to the long-term use of high-dose NSAIDs in our study. Almost half of the patients were using NSAIDs. In the literature, there was no detailed information regarding upper gastrointestinal system disorders in AS.

Furthermore, almost $18 \%$ of the patients had lower gastrointestinal system disorder in this study. A total of $4 \%$ patients had inflammatory bowel disease. Consistent with our study results, it was previously reported that $3.7 \%$ of the patients with AS had inflammatory bowel disease. ${ }^{[17]}$ In another study, the prevalence of inflammatory bowel disease in AS was found to be $6.8 \% \cdot{ }^{[18]}$

An important result of this study was that $22 \%$ of the patients had renal system disorders. The reason for high incidence of renal disorders in patients with AS was the detailed examination of current condition of renal system and previous problems related with kidneys by the CIRS in this study. Several studies indicated that renal complications occurred 5 to $13 \%$ in AS. ${ }^{[1,20]}$ Vilar et al. ${ }^{[21]}$ concluded that renal complications might be seen up to $35 \%$ when employing a broader definition of renal abnormalities. The result of the previous study is consistent with our study findings. The reason for this consistency may be related to detailed examination of all the renal pathologies which were related with AS or not in both studies. In a population-based, retrospective cohort study, renal complications in the male and female patients with AS were reported as $3.4 \%$ and $2.1 \%$, respectively. ${ }^{[22]}$ In the aforementioned study, the ratio of renal complications was suggested more than $72 \%$ in AS patients, compared to the normal population.

The predictors of the severity of comorbidities evaluated by the total CIRS scores were age, disease duration, and functional status as measured by BASFI in this study. There was also a positive correlation between the total score of Ln (CIRS) and age, weekly working hours, history of smoking (pack/year), disease duration, time from diagnosis, BASFI and BASMI scores. There was a negative correlation between total score of Ln (CIRS) and height.

Age and disease duration are significant risk factors in terms of both cardiovascular disorders and mortality in patients with AS. ${ }^{[23,24]}$ Ward et al. ${ }^{[25]}$ suggested that comorbidities increased by the disease duration, and cardiovascular diseases, osteoporosis, diabetes mellitus and cancer frequency were found to be higher in patients with longer disease duration. In the aforementioned study, the most common comorbidities were reported as uveitis (34.7\%), hypertension (23.3\%), depression (15.2\%), peptic ulcer (12.5\%), and bronchial asthma $(9.5 \%)$, respectively. ${ }^{[25]}$

The incidence of comorbidities increases with age and disease duration in patients with AS. The presence of multiple comorbidities leads to increased healthcare cost and mortality, as well. In general, AS begins in younger ages compared to other inflammatory diseases and, thus, it means that patient is exposed to inflammation and the effects of disease throughout most of his/her lifetime. ${ }^{[23]}$ In the present study, we 
found a significant correlation between total score of Ln (CIRS) and age and disease duration, consistent with the literature.

In our study, $63 \%$ of the patients had a history of smoking. In a previous study, the ratio of smoking was reported as $70 \%{ }^{[26]}$ In our study, there was a significant positive correlation between the history of smoking (pack/year) and total score of Ln (CIRS) in patients with AS. Smoking may cause an increase in healthrelated problems in AS. It has been also reported that cigarette smoking is related with increased structural damage in the vertebral column. ${ }^{[27]}$ In addition, smoking is considered to be related to the proximal airway obstruction in AS. ${ }^{[28]}$ Moreover, smoking leads to higher BASDAI and BASFI scores and significantly lower forced vital capacity in AS. ${ }^{[29]}$ Smokers have often worse functional and physical condition compared to non-smokers. ${ }^{[30]}$

Our study has some strengths and limitations. The strength of our study is that, to the best of our knowledge, it is the first study to evaluate comorbidities with CIRS in AS. In our study, comorbidities have been assessed in detail as number and severity. The limitation of our study is, however, that the lack of cause and effect relationship due to the cross-sectional design of the study.

In conclusion, our study results showed that the number of system problems was more than four in AS; however, the severity of system problems were mild. Older age, longer disease duration, and lower functional status were found to be main predictors of comorbidities in our patients. Therefore, these system disorders should be kept in mind in clinical practice.

\section{Declaration of conflicting interests}

The authors declared no conflicts of interest with respect to the authorship and/or publication of this article.

\section{Funding}

The authors received no financial support for the research and/or authorship of this article.

\section{REFERENCES}

1. Feinstein AR. The pre-therapeutic classification of co-morbidity in chronic disease. J Chronic Dis 1970;23:455-68.

2. Fillenbaum GG, Pieper CF, Cohen HJ, Cornoni-Huntley JC, Guralnik JM. Comorbidity of five chronic health conditions in elderly community residents: determinants and impact on mortality. J Gerontol A Biol Sci Med Sci 2000;55:84-9.

3. Ursum J, Nielen MM, Twisk JW, Peters MJ, Schellevis FG, Nurmohamed MT, et al. Increased risk for chronic comorbid disorders in patients with inflammatory arthritis: a population based study. BMC Fam Pract 2013;14:199.
4. Mathieu S, Gossec L, Dougados M, Soubrier M. Cardiovascular profile in ankylosing spondylitis: a systematic review and meta-analysis. Arthritis Care Res (Hoboken) 2011;63:557-63.

5. Bremander A, Petersson IF, Bergman S, Englund $M$. Population-based estimates of common comorbidities and cardiovascular disease in ankylosing spondylitis. Arthritis Care Res (Hoboken) 2011;63:550-6.

6. Kang JH, Chen YH, Lin HC. Comorbidity profiles among patients with ankylosing spondylitis: a nationwide population-based study. Ann Rheum Dis 2010;69:1165-8.

7. Rijken M, van Kerkhof M, Dekker J, Schellevis FG. Comorbidity of chronic diseases: effects of disease pairs on physical and mental functioning. Qual Life Res 2005;14:45-55.

8. Linn BS, Linn MW, Gurel L. Cumulative illness rating scale. J Am Geriatr Soc 1968;16:622-6.

9. Huntley AL, Johnson R, Purdy S, Valderas JM, Salisbury C. Measures of multimorbidity and morbidity burden for use in primary care and community settings: a systematic review and guide. Ann Fam Med 2012;10:134-41.

10. Miller MD, Paradis CF, Houck PR, Mazumdar S, Stack JA, Rifai AH, et al. Rating chronic medical illness burden in geropsychiatric practice and research: application of the Cumulative Illness Rating Scale. Psychiatry Res 1992;41:237-48.

11. Hudon C, Fortin M, Vanasse A. Cumulative Illness Rating Scale was a reliable and valid index in a family practice context. J Clin Epidemiol 2005;58:603-8.

12. Fortin M, Bravo G, Hudon C, Vanasse A, Lapointe L. Prevalence of multimorbidity among adults seen in family practice. Ann Fam Medm2005;3:223-8.

13. Em S, Bozkurt M, Çağlayan M, Oktayoğlu P, Karakoç M, Nas N. The evaluation of comorbid diseases in patients with ankylosing spondylitis. Dicle Med J 2014;41:662-6.

14. Garip Y, Eser F, Dortbas F, Kilicarslan A, Bodur H. Comorbidity profiles among patients with ankylosing spondylitis. Marmara Medical Journal 2016;29:23-8.

15. Braun J, van der Heijde D, Doyle MK, Han C, Deodhar $\mathrm{A}$, Inman $\mathrm{R}$, et al. Improvement in hemoglobin levels in patients with ankylosing spondylitis treated with infliximab. Arthritis Rheum 2009;61:1032-6.

16. Kim KJ, Cho CS. Anemia of chronic disease in Ankylosing Spondylitis: improvement following anti-TNF therapy. Arch Rheumatol 2012;27:90-7.

17. Stolwijk C, Essers I, van Tubergen A, Boonen A, Bazelier MT, De Bruin ML, et al. The epidemiology of extra-articular manifestations in ankylosing spondylitis: a population-based matched cohort study. Ann Rheum Dis 2015;74:1373-8.

18. Stolwijk C, van Tubergen A, Castillo-Ortiz JD, Boonen A. Prevalence of extra-articular manifestations in patients with ankylosing spondylitis: a systematic review and metaanalysis. Ann Rheum Dis 2015;74:65-73.

19. Braun J, Pincus T. Mortality, course of disease and prognosis of patients with ankylosing spondylitis. Clin Exp Rheumatol 2002;20:16-22.

20. Strobel ES, Fritschka E. Renal diseases in ankylosing spondylitis: review of the literature illustrated by case reports. Clin Rheumatol 1998;17:524-30. 
21. Vilar MJ, Cury SE, Ferraz MB, Sesso R, Atra E. Renal abnormalities in ankylosing spondylitis. Scand J Rheumatol 1997;26:19-23.

22. Levy AR, Szabo SM, Rao SR, Cifaldi M, Maksymowych WP. Estimating the occurrence of renal complications among persons with ankylosing spondylitis. Arthritis Care Res (Hoboken) 2014;66:440-5.

23. Lehtinen K. Mortality and causes of death in 398 patients admitted to hospital with ankylosing spondylitis. Ann Rheum Dis 1993;52:174-6.

24. Khan MA, Khan MK, Kushner I. Survival among patients with ankylosing spondylitis: a life-table analysis. J Rheumatol 1981;8:86-90.

25. Ward MM, Learch TJ, Gensler LS, Davis JC Jr, Reveille JD, Weisman MH. Regional radiographic damage and functional limitations in patients with ankylosing spondylitis: differences in early and late disease. Arthritis Care Res (Hoboken) 2013;65:257-65.

26. Divecha H, Sattar N, Rumley A, Cherry L, Lowe GD, Sturrock R. Cardiovascular risk parameters in men with ankylosing spondylitis in comparison with non-inflammatory control subjects: relevance of systemic inflammation. Clin Sci (Lond) 2005;109:171-6.

27. Poddubnyy D, Haibel H, Listing J, Märker-Hermann E, Zeidler H, Braun J, et al. Cigarette smoking has a dosedependent impact on progression of structural damage in the spine in patients with axial spondyloarthritis: results from the GErman SPondyloarthritis Inception Cohort (GESPIC). Ann Rheum Dis 2013;72:1430-2.

28. Eulry F, Marotel C, Lechevalier D, Haguenauer D, Crozes $\mathrm{P}$, Magnin J. [Respiratory involvement in ankylosing spondylarthritis: relations to alpha-1-antitrypsin phenotypes and tobacco consumption]. Rev Rhum Ed Fr 1994;61:405-14.

29. Kaan U, Ferda O. Evaluation of clinical activity and functional impairment in smokers with ankylosing spondylitis. Rheumatol Int 2005;25:357-60.

30. Chen $\mathrm{CH}$, Chen HA, Lu CL, Liao HT, Liu CH, Tsai CY, et al. Association of cigarette smoking with Chinese ankylosing spondylitis patients in Taiwan: a poor disease outcome in systemic inflammation, functional ability, and physical mobility. Clin Rheumatol 2013;32:659-63. 